\title{
There is more to continuing professional development than just scoring hours
}

\author{
Alan Lawrence \\ Founding Editor, Evidence-based Dentistry
}

\begin{abstract}
This issue introduces a new service for readers to enable them to record and verify the time they have spent studying articles in this journal. Around the world, dental registration bodies are beginning to demand that dentists keep up-to-date and be able to prove it. Whereas some states and countries have had a formalised system for a number of years, others so far have not. It is quite clear that in the future dentists will not be able to coast along once they have their basic qualification but will be expected to stay abreast of current knowledge.

Evidence-Based Dentistry (2003) 4, 40-41. doi:10.1038/sj.ebd.6400184
\end{abstract}

Until recently, practitioners tended to update their knowledge in a fairly relaxed manner by supplementing their basic training by browsing though journals and free magazines, topped up by quotes and extracts from advertising materials and persuasive sales representatives. Sleeping through courses was not unknown either! The public were usually blissfully unaware of all of this. The problem with this unstructured approach to learning is that it is all very hit and miss. Cynics have observed that relying on experience alone enables a dentist to make the same treatment mistakes with greater skill, speed and enthusiasm.

It is relatively easy to work out systems to score or verify the time spent learning, but merely attending a course does not necessarily translate into changed practice. Hands-on courses tend to be more popular and dentists report a greater recall - but good intentions made while attending a course tend to be forgotten back in the practice or office. The most frequent forms of Continuing Professional Development (CPD) reported by UK dentists are reading and attending courses. ${ }^{1}$ This information, however, was obtained with a response rate of $54 \%$ from 2000 dentists. What are the non-responders doing? The unsurprising conclusion of the article was that certain groups of dentists would need support to meet the requirements of the UK General Dental Council (GDC) Lifelong Learning Scheme.

The evidence-based approach should benefit practitioners and help them to maximise the time spent studying. As we have pointed out before, the great advantage of looking for evidence to answer a clinical problem, followed by appraising the article yourself, is that you will "own" your learning. You are then much more likely to put what you have learnt into everyday practice. This should lead to greater confidence and job satisfaction.

The simple truth is that there is no single education system or technique that will meet all your professional development requirements. Dentists are individuals with individual needs and any CPD or continuing education (CE) programme must be tailored to meet those needs. This requires a mixture of courses, webbased or computer-aided learning, journal study and problem-based learning. The parallel development of Clinical Audit and Governance schemes provides additional education hours.

The good news is there is a steadily increasing number of high-quality courses, peer-reviewed journals and materials on the web. The bad news is that you can be swamped with the overall increase in courses and journals. Just scoring hours to meet registration requirements is easy and not too expensive. Making your CPD work for you takes more effort but is much more satisfying. Registration Councils or Boards have recognised the need to adopt a flexible and integrated approach using all these different learning methods. A common approach is to divide postgraduate education and study into verified and unverified education as two distinct groups.

\section{GDC requirements for verified CPD}

The GDC in the UK have helpfully defined the essential constituents of verified CPD. ${ }^{2}$ Their requirements are the same for all forms of learning, including distance-learning activities. Any verifiable activity must meet the Council's three educational criteria, which are as follows: 1. The activity must have concise educational aims and objectives: the activity should have a clear purpose or goal;

2. The activity must have clear anticipated outcomes: you should know what you can expect to gain as a result of taking part in the activity;

3. The activity must be subject to quality controls: you should have an opportunity to give feedback with a view to improving quality.

Dentists will have to prove their participation in the activity by obtaining documentary evidence of their participation from the activity-provider, with the number of CPD hours involved. The GDC president pointed out that feedback on the activity to the educator or journal provider is essential and should indicate its value as part of the dentist's professional development. Dentists create the market for postgraduate CPD and, as consumers of $\mathrm{CE}$, are in a position to influence course provision by making experiences and views known. The Evidence-Based Dentistry journal verification system will provide this journal with valuable feedback. This should hopefully improve its usefulness to readers.

Your CPD will divide into keeping upto-date with general advances across dentistry as a whole and with specialist areas/activities of interest, each necessary for a balanced approach. EBD should be able to help you in both of these areas. We have incorporated the GDC's requirements above into our new system, so that time spent studying can be verified too. 


\section{Learning plans}

So what is a good way to manage your CPD? A key step is to develop a learning plan. Although dentists are quite used to developing business plans, which are essential in starting up and developing the financial side of practices, they are less used to applying the same techniques to professional development. Without a plan, however, CPD is a haphazard activity, at best dependent on whatever courses become available and at worst a scoring exercise with little relevance to dentists' needs.

Many professional associations provide proforma learning plans. These vary, but in essence require you to analyse your clinical strengths and weaknesses and to look ahead to see where your skills and practice need developing. This is the classic matrix of Strengths, Weakness, Opportunity and Threats (a SWOT analysis) related to your information and skill needs. A simple way to do this is to draw up a table with the main clinical areas of practice such as diagnosis, radiography, conservation, pain control and so on in one column. This can be refined to include subtopics. Then enter, in parallel columns, scores for how up-todate and how confident you feel about clinical and practical aspects of each topic area. Lastly identify specific problem areas. This analysis will not take long to do but should highlight a number of priority areas. This will focus your search for courses, articles and distance learning.

\section{Portfolios and logbooks}

Another key thing to do is to set up a CPD portfolio. This is a grandiose title and the portfolio can include various components, but it is basically your learning file. It should contain your learning plan, progress notes, details of courses attended, distance-learning activities and practice-based training. One main section will be the logbook. This will have attached the documentary evidence of verified hours spent on CPD. In the case of the UK, that would include the official CPD log sheets. It can be helpful to keep the different types of activities on separate sheets; for example, one for courses, one for journal reading, one for distance-learning, one for practice training activities, etc. Your portfolio can be used to file articles you have obtained and studied and brief notes on your conclusions. A ring binder is ideal for this. In fact over the course of time you will need more than one. This has the supreme advantage of being simple, easy to organise and enables you to review or provide clear evidence of your CPD. Even better when asked by a patient about an issue that you have previously covered as part of your CPD, you can lay your hands on the article in seconds.

\section{Reflective learning}

Another key item stressed by educators is the reflection process. Much of the information gained attending a course or reading an article evaporates quickly. We have limited recall, but notes made at the time but read and considered later in the context of your clinical practice enable you to make sense of what you have learned. You are more likely to think about the relevance of information and how you could change your clinical technique or patient management. This can be enhanced by reviewing the original article or looking at related articles.

The $E B D$ verification system will not only confirm that you have answered the questions and completed the check-list but will provide you with some additional information. If you merely file all of this in your portfolio you will lose a lot of the benefit of your study. The assimilation and reflection process should be completed by examining the copy of your answers, where necessary looking at the original article and considering any further information e-mailed back to you. This process will help you assess and decide how you can translate your conclusions into action. You could share these by setting up a monthly journal club within the practice. Such meetings should include the dental team as appropriate and where possible. They too will need regular CPD to help them develop wider skills and understanding. They will have useful information to contribute. Equally they want to share in-team development. In this way, practice changes will be easier to introduce and will be 'owned' by the whole practice.

\section{Web-based learning}

The Internet can be very useful for accessing information and WWW-based programs. This is a fast developing area. Affordable 'broadband' Internet access will be significant in getting much more rapid access to information and articles. Archived articles online can be down- loaded to subscribers. Dentists will need to improve their IT skills, and time spent on this (where it complies with the GDC criteria) will also count as verified hours.

Dentists and dental practices have suffered in the past from their isolation, distant from postgraduate libraries and information sources. Even when these are available they are rarely used effectively. Fast access to the Internet should greatly improve matters. The information superhighway has been promised for a long time but now it seems this will soon become a practical and easily-used resource for ordinary dentists and not merely the preserve of academics. The whole issue of quality in distance-learning is nicely explored in the report of a workshop of an ad hoc group of users, producers, teachers and researchers. ${ }^{3}$

All of this will mean that the evidencebased approach becomes even more important. Although there are many excellent websites out there, there is also a lot of nonrefereed opinion and sometimes frank disinformation. The Internet is widely used by patients. Your CPD should enable you to answer patients' queries effectively and accurately. You will need to enhance and practise your searching skills. That means learning to ask a focussed question. ${ }^{4}$

Asking the right question and obtaining the relevant articles is of course only part of the process. Information needs to be appraised and, if valid, translated into improved practice. This is where CE turns into professional development, where CPD contributes to real clinical governance. Dentists and members of the dental team have a privileged and protected position as healthcare providers. But protection and respect for the profession will only be maintained if we are seen to protect patients' interests by delivering the best, current and effective healthcare. Governments and the public will not be satisfied with less. Nor should they be.

1. Bullock A, Firmstone V, Fielding A, Frame J, Thomas D, Belfield C. Participation of UK dentists in continuing professional development. Br Dent J 2003; 194:7-51.

2. General Dental Council. Continuing Professional Development Rules. London: General Dental Council: 2001.

3. Eaton KA, Hammick M. Distance learning materials for dentists - a user's guide to quality. Br Dent J 2003; 194:253-256.

4. Richards D. Asking the right question right. Evidence Based Dentistry 2000; 2:20. 